\title{
EDITORIAL: TERRITORIO Y TRANSFORMACIÓN SOCIAL
}

\author{
Claudia Milena Pico Bonilla
}

El mundo al que nos enfrentamos actualmente se mueve en un continuo entre espacios globales y locales cuyas dinámicas no siempre coinciden. Los retos que crean las formas de organización actuales llevan a que no sea posible definir el territorio a partir de los límites geográficos y a que las dimensiones sociales tengan un rol preponderante en la definición de los espacios, la auto-determinación de los grupos sociales y en consecuencia, en los procesos de transformación social.

En este editorial se parte del concepto de construcción social de espacios, esto es, se entiende la dimensión espacial a partir de la interacción entre grupos y la conformación de áreas de construcción con similitudes sociales, culturales y políticas. En palabras de Boisier citado por Álvarez y Rendón (2010, pág. 43):

Construir socialmente una región significa potenciar su capacidad de auto-organización, transformando una comunidad inanimada, segmentada por intereses sectoriales, poco perceptiva de su identificación territorial y en definitiva pasiva, en otra, organizada, cohesionada, consciente de la identidad sociedad región, capaz de movilizarse tras proyectos políticos colectivos, es decir, capaz de transformarse en sujeto de su propio desarrollo.

En ese ejercicio de construcción de la capacidad de auto-organización se estudia un continuo de configuraciones territoriales que van desde el espacio de interacción global y llegan hasta la dimensión municipal. En la dimensión global, se llama la atención sobre la necesidad cada vez más apremiante de inserción de las organizaciones en entornos crecientemente integrados en los que elementos como la identidad regional se diluyen en las lógicas de integración comercial y cultural propias de la globalización (CEPAL, 2002).

En esta dimensión más amplia suelen preocupar las tendencias a la homogenización de prácticas sociales y empresariales para atender a una competencia cada vez más aguda en la que las lógicas de poder propias de modos de producción como el capitalista se imponen. Las dinámicas de productividad y las leyes de funcionamiento de mercado se trasladan incluso a sectores en los que dichas formas de organización parecen oponerse a la naturaleza de las organizaciones. Tal vez el caso más evidente es el de las Universidades, cuyo origen y naturaleza apuntan a la generación de ideas que transformen desde el pensamiento crítico pero que, en virtud de los procesos previamente descritos, terminan convirtiéndose en centros de reproducción de las lógicas de mercado y con necesidades apremiantes de normalización que vuelven la competencia mundial un esquema amorfo de construcción territorial a nivel global con normas comunes de organización que no se suscriben a un espacio físico.

En estas dinámicas y en el continuo de configuraciones territoriales coinciden además espacios con características culturales y sociales comunes que en su afán por abandonar su condición periférica incluyen en sus prácticas procesos de integración tendientes a la eliminación de la diferencia y a la emulación de 
prácticas comunes en otros espacios con atributos de centro. La tendencia centro periferia descrita se ve reflejada no solo en los entornos universitarios, también se manifiesta en un mercado de capitales cuya omnipresencia ha llevado a una sobreabundancia de recursos en un entorno de fuertes restricciones a las posibilidades de inversión (Friedman, 2020).

Las dinámicas globales parecen así una tendencia imposible de eludir hacia la homogenización. No obstante, las tendencias locales se resisten a ser homologadas a las formas de hacer y ser mundiales y a las implacables normas de la competencia. Cada territorio tiene sus demandas, algunas relacionadas con las condiciones políticas y las luchas por el poder y otras con los procesos de toma de decisiones para garantizar el bienestar de cada uno de sus miembros.

Así las cosas, se puede afirmar que, si bien las tendencias mismas del modo de producción crean demandas internacionales que estimulan modelos de organización homogéneos en los que las fronteras geográficas se reemplazan por formas comunes de hacer y ser, la realidad muestra territorios que resisten en su propia complejidad y que se configuran de conformidad con las dinámicas que impone su realidad histórica y social, se crean así reductos de grupos sociales que construyen su propia identidad y se organizan en torno a ella.

El reto para las organizaciones, empresas y grupos sociales es encontrar un balance entre la respuesta a las demandas del sistema internacional de mercado y la conformación de órdenes fundados en sus particularidades. Esto es, la creación de espacios que más allá de la geografía creen dinámicas de organización que atiendan a las complejidades territoriales y que contribuyan al cambio social que no se va a producir si se mantiene esa obsesión por la creación de formas únicas de organización que reflejan un sistema de mercado cuyas fracturas se han hecho cada vez más evidentes en las crisis recurrentes a las que se enfrenta el mundo contemporáneo.

Esta edición de Punto de Vista hace un recorrido desde los procesos de normalización asociados con las necesidades de internacionalización de las Universidades y pasa por las necesidades de integración y la respuesta periférica a las demandas internacionales con el análisis de la experiencia del Mercado Integrado Latinoamericano (MILA).

Posteriormente, se centra en el examen de realidades más locales en las que se exploran los cambios institucionales para la reconstrucción económica de zonas afectadas por el prolongado conflicto armado colombiano y sus dinámicas sociales. También se discuten las necesidades de formación para hacer frente a los riesgos en Bogotá. La edición cierra con un estudio de caso en el que un proceso de decisión sobre localización incide en el bienestar de trabajadores y empresario y da cuenta de la complejidad de las estructuras sociales más pequeñas y de sus retos cotidianos.

\section{REFERENCIAS}

Álvarez, R., \& Rendón, J. (2010). El territorio como factor de desarrollo. Semestre económico, 13(27), 39-62. CEPAL. (2002). Globalización y Desarrollo. Brasilia: Naciones Unidas- CEPAL.

Friedman, G. (2020). The storm before the calm. New York: Penguin Random House. 